\title{
BMJ Global Health Associations between low HDL, sex and cardiovascular risk markers are substantially different in sub-Saharan Africa and the UK: analysis of four population studies
}

\author{
Rosamund Greiner, ${ }^{1}$ Moffat Nyirenda, ${ }^{2}$ Lauren Rodgers, ${ }^{3}$ Gershim Asiki, ${ }^{4}$ \\ Louis Banda, ${ }^{5}$ Beverley Shields, ${ }^{1}$ Andrew Hattersley, ${ }^{1}$ Amelia Crampin, ${ }^{5}$ \\ Robert Newton (iD) , ${ }^{2}$ Angus Jones (i) ${ }^{1}$
}

To cite: Greiner R, Nyirenda M, Rodgers L, et al. Associations between low HDL, sex and cardiovascular risk markers are substantially different in sub-Saharan Africa and the UK: analysis of four population studies. BMJ Global Health 2021;6:e005222. doi:10.1136/ bmjgh-2021-005222

Handling editor Sanni Yaya

- Additional material is published online only. To view, please visit the journal online (http://dx.doi.org/10.1136/ bmjgh-2021-005222).

RG, MN, AC, RN and AJ contributed equally.

Received 31 January 2021 Revised 11 April 2021 Accepted 5 May 2021

Check for updates

C Author(s) (or their employer(s)) 2021. Re-use permitted under CC BY-NC. No commercial re-use. See rights and permissions. Published by BMJ.

For numbered affiliations see end of article.

Correspondence to Dr Angus Jones; angus.jones@exeter.ac.uk

\section{ABSTRACT}

Introduction Low high-density lipoprotein (HDL) is widely used as a marker of cardiovascular disease risk, although this relationship is not causal and is likely mediated through associations with other risk factors. Low HDL is extremely common in sub-Saharan African populations, and this has often been interpreted to indicate that these populations will have increased cardiovascular risk. We aimed to determine whether the association between $\mathrm{HDL}$ and other cardiovascular risk factors differed between populations in sub-Saharan Africa and the UK.

Methods We compared data from adults living in Uganda and Malawi $(n=26216)$ and in the UK $(n=8747)$. We examined unadjusted and adjusted levels of HDL and applied the WHO recommended cut-offs for prevalence estimates. We used spline and linear regression to assess the relationship between HDL and other cardiovascular risk factors.

Results HDL was substantially lower in the African than in the European studies (geometric mean 0.9$1.2 \mathrm{mmol} / \mathrm{L}$ vs $1.3-1.8 \mathrm{mmol} / \mathrm{L})$, with African prevalence of low HDL as high as $77 \%$. Total cholesterol was also substantially lower (geometric mean $3.3-3.9 \mathrm{mmol} / \mathrm{L}$ vs 4.6-5.4 mmol/L). In comparison with European studies the relationship between HDL and adiposity (body mass index, waist to hip ratio) was greatly attenuated in African studies and the relationship with non-HDL cholesterol reversed: in African studies low HDL was associated with lower non-HDL cholesterol. The association between sex and HDL was also different; using the WHO sex-specific definitions, low HDL was substantially more common among women $(69 \%-77 \%)$ than men $(41 \%-59 \%)$ in Uganda/Malawi.

Conclusion The relationship between HDL and sex, adiposity and non-HDL cholesterol in sub-Saharan Africa is different from European populations. In sub-Saharan Africans low HDL is a marker of low overall cholesterol and sex differences are markedly attenuated. Therefore low HDL in isolation is unlikely to indicate raised cardiovascular risk and the WHO sex-based cut-offs are inappropriate.

\section{Key questions}

What is already known?

- A number of studies have shown a high prevalence of low high-density lipoprotein (HDL) in sub-Saharan African populations despite low levels of obesity.

- In other populations, low HDL is strongly associated with higher non-HDL cholesterol, obesity and increased cardiovascular risk, and HDL is substantially lower in men than in women.

- The relationship between low HDL and cardiovascular risk is not causal and is therefore mediated through associations with other causal risk factors.

\section{What are the new findings?}

- This study demonstrates using data from two subSaharan African countries and two European studies the different associations between HDL and other cardiovascular risk factors, with low HDL associated with lower non-HDL cholesterol.

- Our findings also demonstrate that HDL differences between men and women documented in many populations are markedly reduced in sub-Saharan African studies.

What do the new findings imply?

- Lower HDL in sub-Saharan African populations is part of a pattern of lower overall cholesterol.

- Until prospective studies of cardiovascular outcomes are available, isolated low HDL in sub-Saharan Africans should not be taken to indicate raised cardiovascular risk.

- Current WHO thresholds for low HDL, which differ substantially by sex, do not appear appropriate for this population.

\section{INTRODUCTION}

The inverse relationship between highdensity lipoprotein (HDL) and cardiovascular disease (CVD) is well established in European and North American populations. ${ }^{12}$ While low HDL is strongly associated with CVD 
risk, Mendelian randomisation and trials of HDL-raising agents have demonstrated that HDL is not causally associated with cardiovascular risk, and therefore the relationship between low HDL and higher cardiovascular risk is likely to be driven by other factors associated with low HDL, such as increases in non-HDL cholesterol and lowdensity lipoprotein (LDL) ${ }^{3-6}$ Despite the lack of causal association HDL remains a strong predictor of cardiovascular risk that is widely used in cardiovascular risk prediction. ${ }^{37}$ Low HDL in studied populations is associated with other cardiovascular risk factors, such as obesity and ectopic fat deposition, high non-HDL cholesterol and LDL, high triglycerides, and hypertension. ${ }^{8}$

A number of studies have shown that low HDL is common in sub-Saharan African populations. ${ }^{9-15}$ Low HDL is by far the most common dyslipidaemia in subSaharan Africa. ${ }^{11}$ This has been interpreted by many as an indicator of escalating CVD risk, driven by increasing urbanisation, westernisation of diets and increasingly sedentary lifestyles. ${ }^{11}{ }^{14}$ However, low HDL in these populations is often much more prevalent than other CVD risk predictors, such as obesity and high LDL cholesterol and triglycerides. ${ }^{101215}$ In addition, while low HDL is strongly associated with increasing adiposity in European, North American, Indian and Chinese populations, sub-Saharan African studies have found a high prevalence of low HDL even among predominantly thin rural dwellers and in those with low body mass index (BMI). ${ }^{9} 14$ 16-23

We aimed to determine whether the relationship between HDL and other cardiovascular risk factors differs between two populations in sub-Saharan Africa, where low HDL is widespread, and a European population.

\section{METHODS}

\section{Study design and participants}

We assessed the relationship between HDL and cardiovascular risk factors in population studies from Malawi and Uganda and compared these relationships with UK studies. Included studies (with the exception of the Exeter Family Study, EFS) were population studies (described in the next section), and participants were excluded from this analysis if they were aged under 18 , were HIV-positive, reported pregnancy at the time of data collection or had diabetes. Individuals missing sex and lipid data were excluded from analysis. After these exclusions, 21608 participants remained in the Malawian study (10428 rural and 11180 urban), 4608 in the Ugandan cohort, 1459 in the UK family study and 7288 in the Exeter 10,000 cohort (EXTEND). A flow chart demonstrating the effect of these exclusion criteria is shown in online supplemental figure 1.

\section{Data collection}

Data collection methods for each of the studies have been described in detail elsewhere. ${ }^{24-26}$ All studies were cross sectional and collected survey data on sociodemographic variables, anthropometric measurements and a fasted blood sample. ${ }^{24-26}$

\section{MEIRU Urban/Rural NCD Survey, Malawi}

In Malawi, rural participants were recruited through an existing demographic surveillance site and urban participants were invited to partake through a full enumeration of Area 25 of the capital city, Lilongwe, as previously described. ${ }^{25}$ All participants were aged $\geq 18$ at recruitment. If participants had not fasted, they were revisited, and if they had not fasted on the second occasion a random blood sample was collected. Laboratory analysis of lipids was undertaken by the Malawi Epidemiology and Intervention Research Unit (MEIRU) laboratory using enzymatic assays on the Beckman Coulter Chemistry Analyser. ${ }^{27}$ Lipids were measured in all participants consenting to a blood sample (24 982 of 31012 cohort participants).

\section{Masaka General Population Cohort, Uganda}

In Uganda, all resident individuals aged $\geq 13$ in the study area of the General Population Cohort were invited to participate in the study, as previously described. ${ }^{24}$ Lipids were measured using enzymatic, colourimetric assays on the Cobas Integra 400 analyser. ${ }^{28}$ Lipid analysis was undertaken in all adults in the 2011 survey round consenting to a blood sample (5856 adult participants).

\section{Exeter 10,000 , UK}

The EXTEND study was an unselected population cohort recruited in the South West of England from the community and from primary care settings. Lipids were analysed by the Blood Sciences Laboratory of the Royal Devon and Exeter NHS Foundation Trust using enzymatic, colourimetric assays on the Roche Cobas system.

\section{Exeter Family Study, UK}

In the EFS, all resident white women in Exeter without diabetes with a singleton pregnancy were invited to the study, along with their partners. ${ }^{26}$ Data were collected from mothers after birth (in order to obtain data from outside of pregnancy, mean follow-up time was 6 years and 5 months after birth). Total cholesterol, HDL and triglycerides were directly measured by the Blood Sciences Laboratory of the Royal Devon and Exeter NHS Foundation Trust using enzymatic, colourimetric assays on the Roche Cobas system.

LDL cholesterol in all studies was estimated by modified Friedewald formula. Non-HDL cholesterol was calculated for all studies by subtracting HDL from total cholesterol.

\section{Statistical analysis}

Definitions of dyslipidaemia and obesity

BMI categories, low HDL, high total cholesterol, triglycerides and high blood pressure were defined by the WHO cut-offs. ${ }^{29}$ BMI was defined as underweight if it was $<18.5$, normal from 18.5 to $<25$, overweight from 25 to $<30$, and obese $\geq 30$. Low HDL was defined as $<1.03 \mathrm{mmol} / \mathrm{L}$ for men and $<1.29 \mathrm{mmol} / \mathrm{L}$ for women. Total cholesterol was 
defined as high if it was $\geq 6.2 \mathrm{mmol} / \mathrm{L}$. High triglycerides was defined as $\geq 1.7 \mathrm{mmol} / \mathrm{L}$. The WHO does not use a specific definition of high LDL, but in a recent review of dyslipidaemias in sub-Saharan Africa the most commonly used diagnostic cut-off was $3.3 \mathrm{mmol} / \mathrm{L}$, which is in line with the guidance of the US National Cholesterol Education Program. ${ }^{11}$ High blood pressure was defined as systolic blood pressure $\geq 140 \mathrm{~mm} \mathrm{Hg}$ and/or diastolic $\geq 90 \mathrm{~mm} \mathrm{Hg}$ or on antihypertensive medication. ${ }^{29}$

\section{Analysis}

Analysis is based on participants with complete lipid data. Men and women were analysed separately due to the existing evidence of a sex difference in HDL. ${ }^{30}$ Additionally, rural and urban participants in the Malawian cohort were analysed separately as there is evidence of a relationship between location of residence and lipid profile. ${ }^{142}$ Non-normally distributed variables were log-transformed and geometric means and $95 \%$ CIs are reported if logtransformed variables were normally distributed. Log age remained highly skewed, so median and IQR are reported. Unadjusted baseline characteristics of men and women in each cohort are reported. The geometric mean HDL for each cohort, adjusted to the average age and BMI and smoking status of the Malawian cohort, is also reported, alongside analysis that also adjusted for alcohol consumption. The association of HDL with deprivation was explored separately in each cohort, as these studies used different measures of assessing deprivation. Spline regressions with $3 \mathrm{df}$ were plotted to explore the relationships between CVD risk factors in each cohort separately for men and women. Where relationships were linear, linear regression analysis was conducted and $\beta$-coefficients with $95 \%$ CIs are reported. Sensitivity analysis were carried out. We conducted identical analyses excluding participants using lipid-lowering medication and individuals who consumed alcohol daily.

\section{Software}

Statistical analysis was performed and data visualisations created using Stata SE V.16.0 and R, using RStudio V.1.2.5001.

\section{Patient and public involvement}

Patients and/or the public were not involved in the design, conduct, reporting or dissemination of this research.

\section{RESULTS}

\section{Participant characteristics}

The characteristics of the included participants are shown in table 1. Participants in the EXTEND study were substantially older than other studies, with BMI higher in the UK than in African studies. One hundred per cent of participants in the Malawian and Ugandan studies were black African, while 100\% of those in EFS and $98 \%$ of those in EXTEND were white European. Smoking was less common among women in all studies.

\section{Missing data and exclusion criteria}

Online supplemental figure 1 shows the effect of study inclusion criteria and missing data. Of 42001 meeting the study inclusion criteria (aged over 18, not pregnant, HIV-negative and did not have diabetes), 7045 could not be included in analysis due to missing data. The characteristics of participants with missing data were similar to the included participants (online supplemental table 1).

\section{Low HDL is highly prevalent in sub-Saharan African populations}

Table 2 shows the lipid levels and the prevalence of dyslipidaemia by the WHO definitions for men and women in the included studies. Despite low overall prevalence of obesity, HDL was consistently lower in all of the groups in the African studies than in the UK. Total cholesterol was also substantially lower in African studies, with the ratio of total cholesterol to HDL broadly similar in men from the UK and sub-Saharan Africa, but higher in subSaharan African women than those from the UK. Low HDL was extremely common in African studies, ranging from $41 \%$ to $77 \%$ of participants across studies and sex (table 2) ${ }^{29}$ This is in contrast to the UK studies where low HDL was infrequent (10\%-17\%). In contrast, other dyslipidaemias were less common in the African studies, with 12\%-21\% of Malawian study participants and only $4 \%-11 \%$ of Ugandans having raised LDL, while in the UK studies the prevalence of high LDL was 14\%-43\% (table 2). This is despite $15 \%$ of men and $6 \%$ of women in EXTEND using lipid-lowering medication, compared with $0 \%-0.5 \%$ in each of the sub-Saharan African studies (these data were not available for participants in the EFS). Among the sub-Saharan African studies, 5\%-15\% had raised triglycerides by the WHO definitions, compared with $5 \%-28 \%$ in the UK studies (table 2 ). ${ }^{29}$

\section{Differences in HDL between UK and African studies were not explained by known potential confounders}

In the analysis adjusted for age, BMI and smoking status, estimates were similar, with marked differences in HDL between African and UK populations (figure 1; adjusted for age only in online supplemental figure 2). While lack of comparable measures meant we could not adjust across studies to assess the effects of socioeconomic status, this was not substantially associated with HDL within individual studies-where there were statistically significant results, the effect sizes were negligible (online supplemental table 2). Self-reported alcohol consumption was recorded in Malawi, Uganda and in the EXTEND study, and the results were similar with additional adjustment for alcohol consumption in these studies (online supplemental figure 3 ).

\section{Sex differences in HDL seen in European populations are reduced in sub-Saharan African studies}

In the UK studies, HDL was substantially higher in female participants (table 2), consistent with the gender-specific thresholds used to define low HDL internationally. ${ }^{31}$ In 


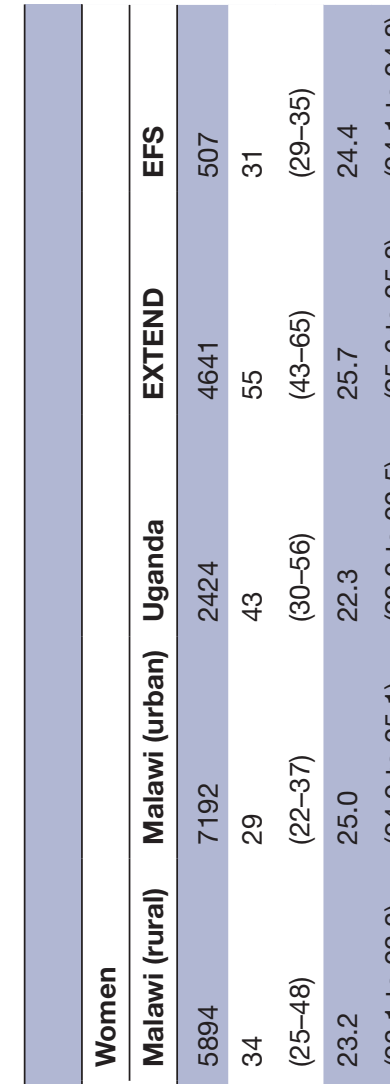

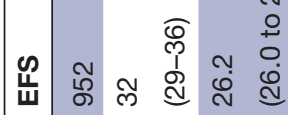

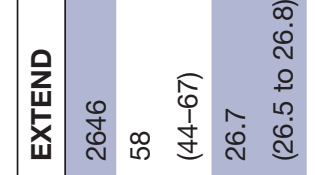

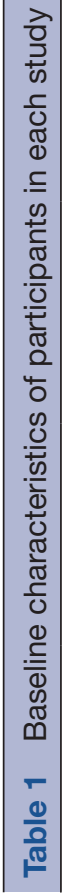

बi

ลุ

(2) ल)

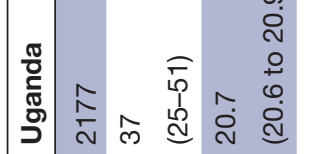

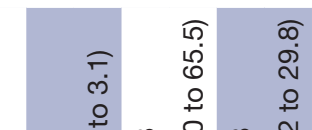

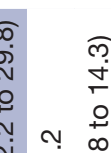

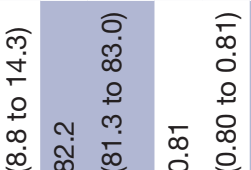

$-0 \dot{0}$ है

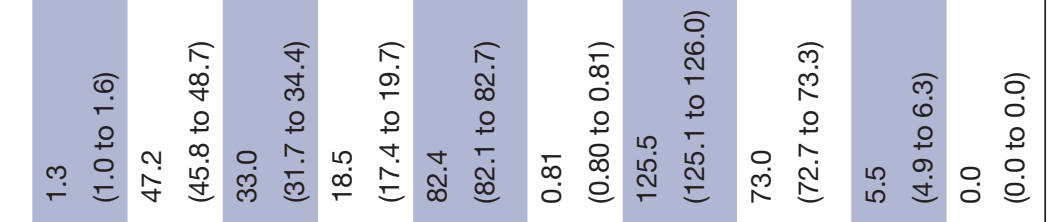

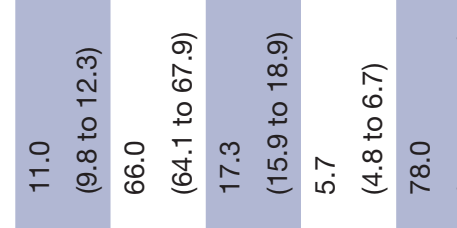

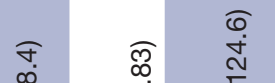

$\widehat{0}$

(1)

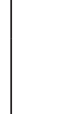

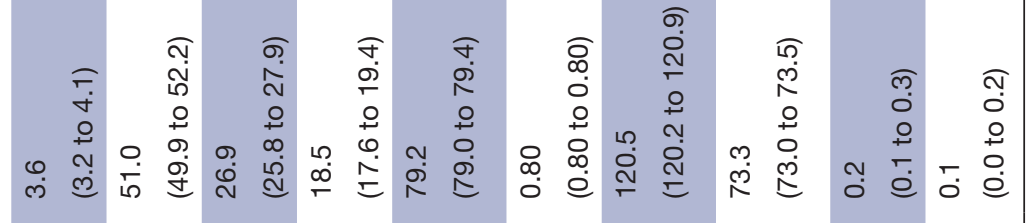

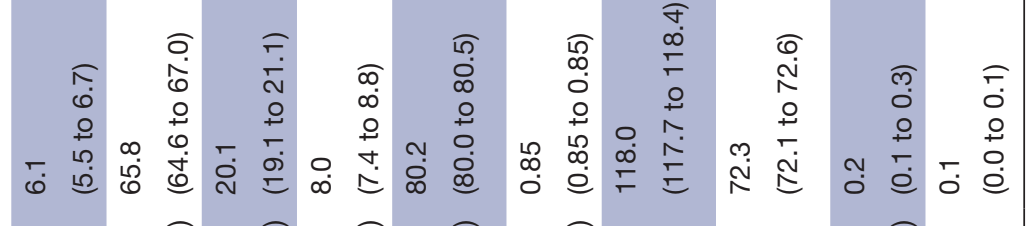

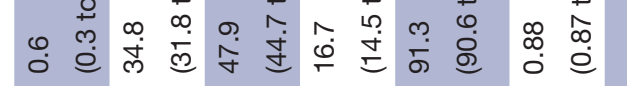

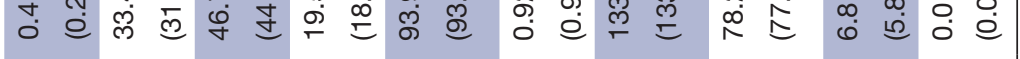

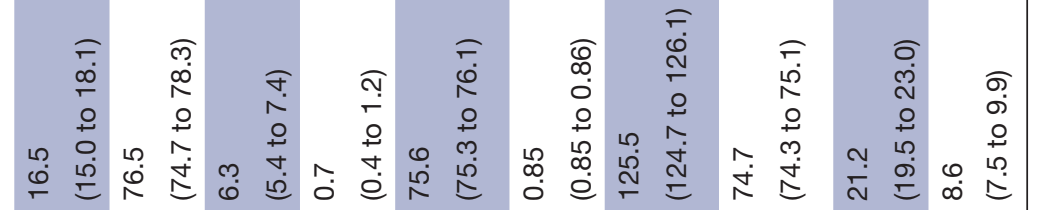




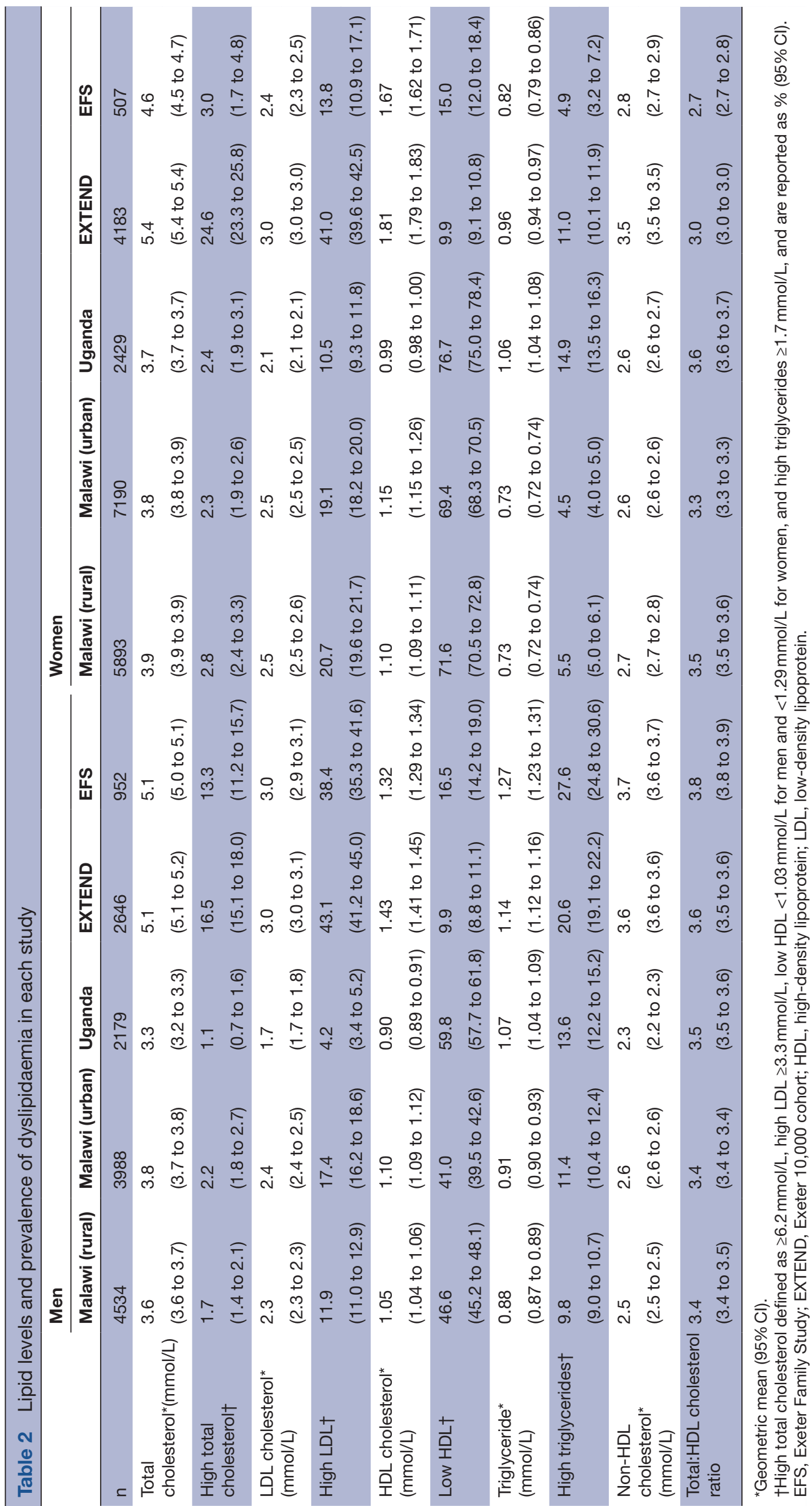




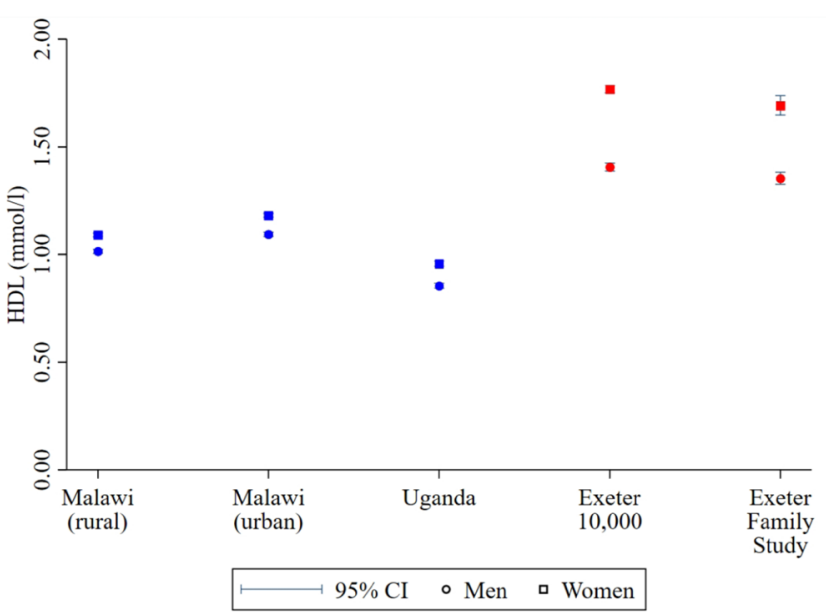

Figure 1 Geometric mean high-density lipoprotein (HDL) for each cohort, adjusted to the median age (31 years) and geometric mean body mass index $\left(23.21 \mathrm{~kg} / \mathrm{m}^{2}\right)$ of the Malawian cohort. All studies were adjusted for smoking status, apart from female participants in the Exeter Family Study, for whom smoking data were not available.

contrast, in African studies there were only minor differences in HDL between genders. For example in Malawian populations the geometric mean HDL was 1.05 and 1.10 in men and women, respectively, in the rural site and 1.10 and 1.15 in the urban site (table 2). This meant that using the WHO definitions of low HDL, which specify a higher cut-off for women than men, the prevalence of low HDL was markedly higher in women than in men in African studies. For example in Malawi the prevalence of 'low' HDL using the WHO criteria was $69 \%-77 \%$ in women and $41 \%-59 \%$ in men. In contrast, among the UK studies there was a similar prevalence of low HDL between men and women using WHO criteria.

\section{The relationship between adiposity and HDL is substantially different between European and African studies}

In the UK, as expected, a clear inverse relationship between BMI and HDL was observed in both men and women; in comparison this was near absent in all of the African groups (figure 2 for spline regression and online supplemental table 3 for linear regression with and without adjustment for age, smoking status and alcohol consumption). These findings were similar when waist to hip ratio is used as a measure of adiposity in place of BMI (online supplemental figure 4). In linear regression analysis the $\beta$-coefficients for the relationship between BMI and HDL were significantly lower in the sub-Saharan African studies than in the UK in unadjusted analysis ( $\beta$-coefficient $(95 \% \mathrm{CI})$ among men: $-0.034(-0.037$ to $-0.031)$ in the UK and $-0.007(-0.009$ to -0.005$)$ in subSaharan Africa; among women: -0.031 ( -0.034 to -0.029$)$ in the UK and $-0.004(-0.005$ to -0.003$)$ in sub-Saharan Africa; online supplemental table 3). The results were similar when adjusted for age, smoking status and alcohol consumption (online supplemental table 3).

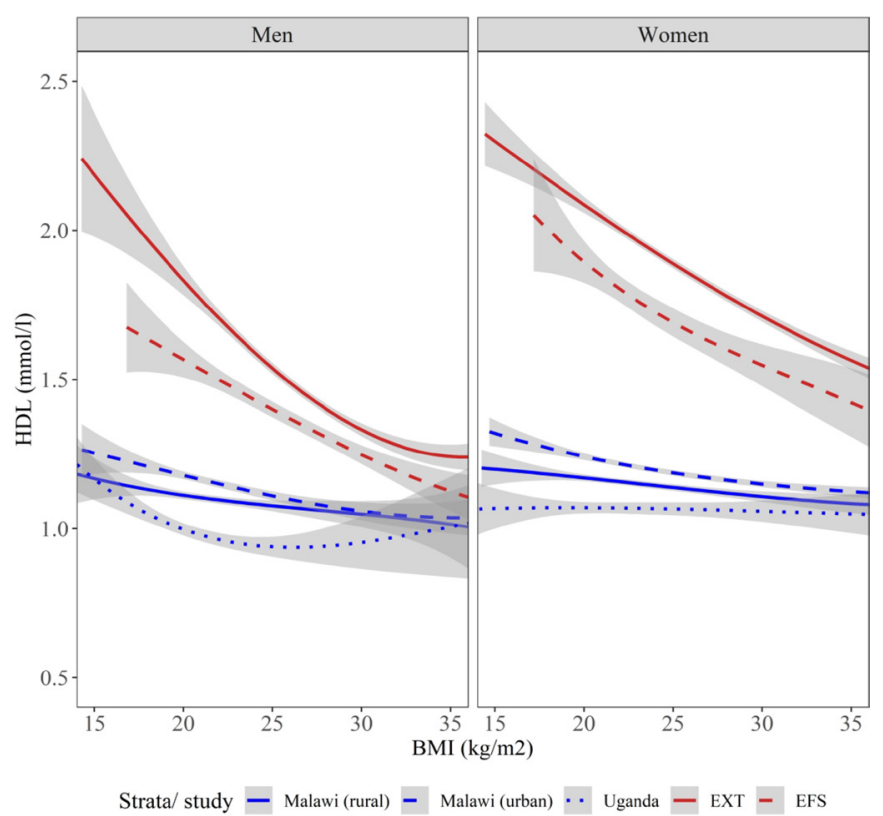

Figure 2 Spline regression showing HDL at each level of BMI for each cohort. BMI, body mass index; EFS, Exeter Family Study (UK); EXT, Exeter 10,000 study (UK); HDL, highdensity lipoprotein.

In contrast, the relationship between BMI and triglycerides was broadly similar across all of the studies in both men and women, with triglycerides increasing with increasing BMI (figure 3).

\section{The relationships between HDL and other lipids are markedly different in UK and African studies}

In UK studies there is a strong inverse relationship between HDL and non-HDL cholesterol. In marked contrast, this relationship reversed in African studies, where low HDL is associated with lower non-HDL cholesterol (figure 4). This was similar for calculated LDL (online supplemental figure 5). In linear regression analysis, the $\beta$-coefficients for the relationship were substantially different in unadjusted analysis ( $\beta$-coefficient (95\% CI) among men: $-0.089(-0.100$ to -0.078$)$ in the UK and +0.046 (0.038 to 0.054) in sub-Saharan Africa; among women: -0.069 ( -0.081 to -0.057$)$ in the UK and +0.041 (0.036 to 0.047 ) in sub-Saharan Africa), and this difference remained in adjusted analysis (online supplemental table 2). While lower HDL was associated with higher triglycerides for all studies, the magnitude of the relationship between HDL and triglycerides is far smaller in sub-Saharan African participants (figure 5). In linear regression analysis, the $\beta$-coefficients for the relationship between triglycerides and HDL were substantially reduced in the sub-Saharan African studies compared with the UK, both in unadjusted analysis ( $\beta$-coefficient (95\% CI) among men: $-0.243(-0.259$ to -0.227$)$ in the UK and -0.075 ( -0.085 to -0.064$)$ in sub-Saharan Africa; among women: $-0.327(-0.350$ to -0.305$)$ in the UK and $-0.119(-0.128$ to -0.109$)$ in sub-Saharan Africa) and in adjusted analysis (online supplemental table 2). These 


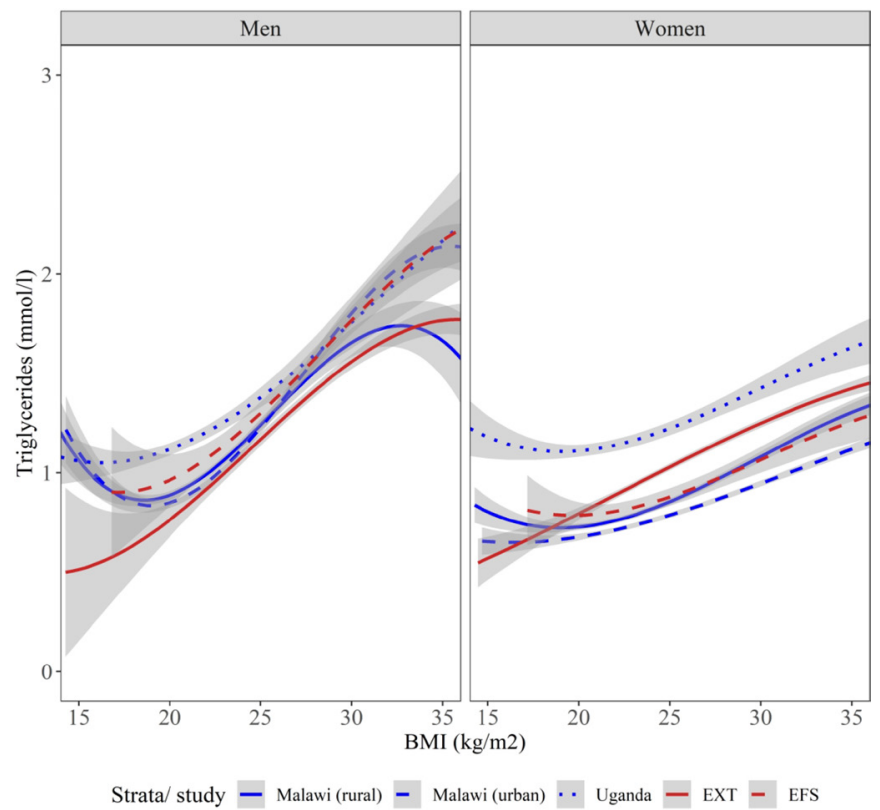

Figure 3 Spline regression showing triglycerides at each level of BMI for each cohort. BMI, body mass index; EFS Exeter Family Study (UK); EXT, Exeter 10,000 study (UK).

results were similar in a sensitivity analysis in which we excluded participants who were using lipid-lowering medication (online supplemental figures $6-8$ and table 4).

In each of the studies that had blood pressure values available, the relationship to HDL was broadly similar, with a very modest increase in HDL with higher blood pressure (online supplemental figure 9 ).

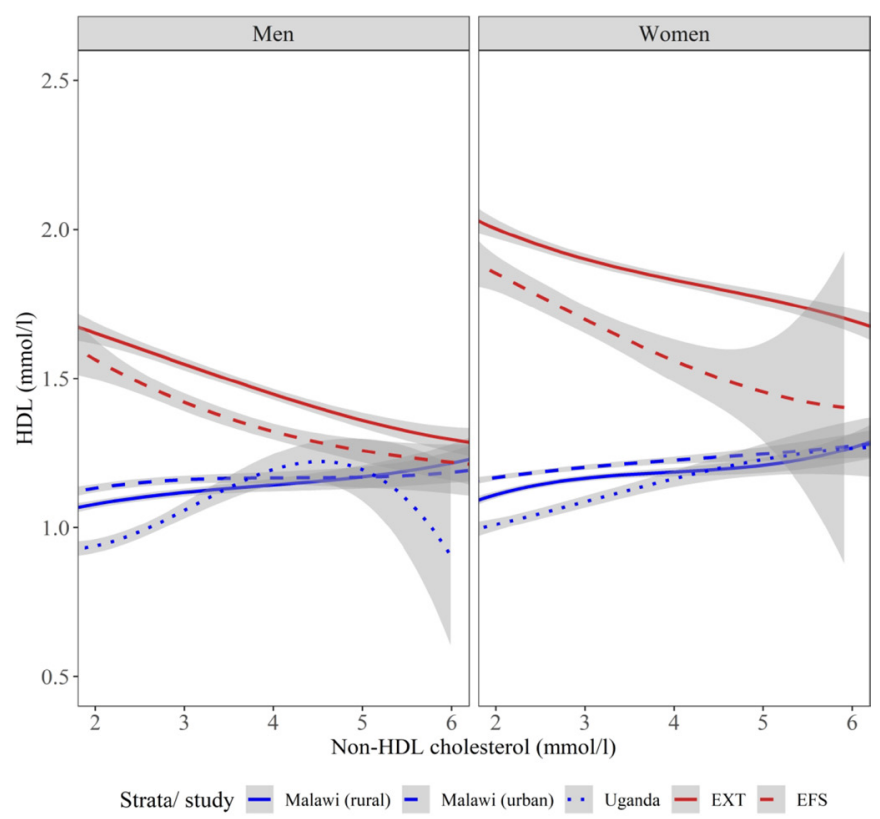

Figure 4 Spline regression showing HDL at each level of non-HDL for each cohort. EFS, Exeter Family Study (UK); EXT, Exeter 10,000 sudy (UK); HDL, high-density lipoprotein.

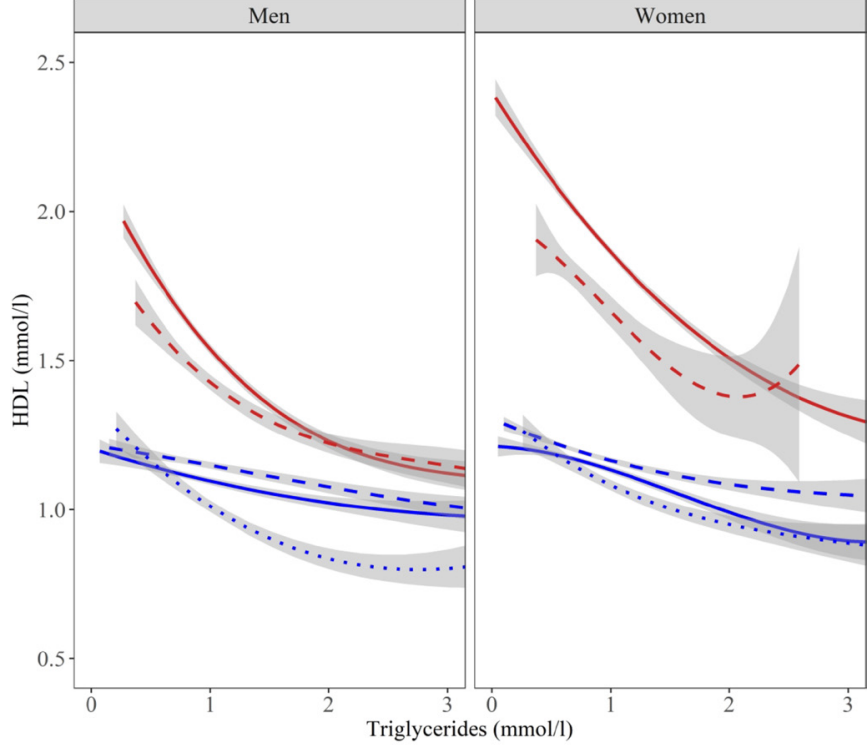

Strata/study - Malawi (rural) - Malawi (urban) $\cdots$ Uganda - EXT - EFS

Figure 5 Spline regression showing HDL at each level of triglycerides for each cohort. EFS, Exeter Family Study (UK); EXT, Exeter 10,000 study (UK); HDL, high-density lipoprotein.

\section{DISCUSSION}

In these large community studies, HDL was substantially lower in sub-Saharan Africa than in the UK, despite the markedly lower overall prevalence of obesity and other dyslipidaemias. In African cohorts low HDL appears to largely reflect lower overall lipids and the association between HDL and other risk factors is substantially different: in contrast to UK studies, in sub-Saharan African participants a low HDL is associated with lower non-HDL cholesterol. Given the strong causal relationship between the major components of non-HDL cholesterol and cardiovascular risk, this suggests that isolated low HDL is unlikely to indicate increased cardiovascular risk in sub-Saharan African populations.

\section{Comparison with previous research}

Our findings of a high prevalence of HDL below the WHO thresholds are consistent with previous studies in sub-Saharan African populations which suggest this is common across sub-Saharan Africa and not confined to the East and Southern African populations included in this research. ${ }^{91416222331-34}$ This appears to be the case at different stages of economic development, with half of black South Africans reported to have low HDL. ${ }^{33}$ Our finding of a weaker relationship between BMI and HDL in sub-Saharan African studies in comparison with the UK is consistent with studies in other sub-Saharan African countries showing that low levels of HDL are common among individuals with low BMI ${ }^{116}$ and studies demonstrating lower levels of HDL in rural dwellers than urban, despite urban residence usually being associated with increased levels of obesity. ${ }^{1422} 2331$ This is also constant with recent analysis comparing the relationship between lipids and both BMI and waist to hip ratio in 
Malawi compared with the UK, using the same Malawian cohort. $^{15}$

Our findings within people living in Africa are in contrast to studies of people of African origin living in high-income countries. Black African migrants to highincome countries have higher HDL levels than people of their ethnic origin in sub-Saharan African, although they have higher BMI. ${ }^{31} 35$ For example, individuals of Ghanaian descent who live in European capitals have significantly higher HDL concentrations than those who live in rural and urban Ghana. ${ }^{31}$ Similarly, low HDL is less common among West African migrants in North America than in Africans in Africa. ${ }^{35}$ A number of studies in Europe have shown that people of black African descent have similar or more favourable lipid profiles (including higher HDL) than Caucasians. ${ }^{36-41}$

Although novel genetic associations with HDL in subSaharan Africa have been reported, the very different finding in African origin populations living in highincome countries suggests that differences in HDL levels and associations are of environmental, rather than genetic, origin. ${ }^{42}$ The specific environmental exposures that drive these changes are unclear. Potential explanations may include dietary differences; for example, low fat intake may result in reduced HDL cholesterol, and this dietary pattern is common in sub-Saharan Africa. ${ }^{434}$ A further potential explanation is the effects of infection or inflammation, which have been shown to be associated with a decrease in HDL. ${ }^{45}$ It is, however, intriguing that this is not substantially influenced by rural or urban dwelling and habits. The different association between low HDL and other characteristics like sex, BMI and nonHDL cholesterol also suggests a unique pathway with the context of Africa.

\section{Strengths and weaknesses}

A strength of this study is that it compares large, wellcharacterised population studies from one East and one Southern African country with comparison studies from the UK and include both rural and urban populations. The findings of this study are consistent across the African studies. Limitations of our study include our African studies only representing two countries; however, given that highly prevalent low HDL has been reported widely in different African populations, it is likely findings may be more broadly applicable. A further limitation is that there were limited data available to enable exploration of factors that might explain these differences; for example, most studies did not collect detailed dietary data and one study lacked data on alcohol consumption. Given migration data suggest that genetic differences appear unlikely to explain our findings, exploring the potential impact of further environmental exposures such as diet, exposure to infection or early undernutrition is an important area for future research, alongside assessment of HDL functionality and subclass in sub-Saharan African populations. ${ }^{9} 1043-47$ Lastly, participants in the EXTEND study were older than those in the other studies; however, the results were similar in the EFS and in the age-adjusted analysis.

\section{Implications}

Our findings raise doubts that low HDL in isolation will indicate high cardiovascular risk in the African population studied: as those with low HDL have lower non-HDL, it is likely they will be at lower rather than higher cardiovascular risk and that the use of prediction tools that incorporate HDL developed in other populations may be inappropriate. ${ }^{48}$ Prospective studies that assess the relationship between lipids and future CVD outcomes in subSaharan African populations are needed to determine the optimal approaches to cardiovascular risk prediction in this region. Our results suggest that clinicians should not use low HDL in isolation to signify cardiovascular risk, until such point as much needed prospective studies become available. Our findings also suggest the WHO thresholds used internationally for defining low HDL may be inappropriate for sub-Saharan African populations, defining most of the population as low, with a marked discrepancy by sex consistent with the loss of sexbased variation in HDL in this population. Other definitions relying on HDL (such as metabolic syndrome) will therefore also be inappropriate.

\section{CONCLUSIONS}

In conclusion, the relationship between HDL, sex and cardiovascular risk factors is markedly different in subSaharan Africa, with low HDL a marker of low overall cholesterol, and the large sex differences seen elsewhere in the world were not observed. Therefore low HDL is unlikely to be a reliable marker of cardiovascular risk in this region, and sex-based cut-offs recommended by the WHO are unlikely to be appropriate.

\section{Author affiliations}

${ }^{1}$ Institute of Biomedical and Clinical Science, University of Exeter Medical School, Exeter, UK

${ }^{2}$ MRC/UVRI and LSHTM Uganda Research Unit, Entebbe, Uganda

${ }^{3}$ Institute of Health Research, University of Exeter Medical School, Exeter, UK

${ }^{4}$ African Population and Health Research Center, Nairobi, Kenya

${ }^{5}$ Malawi Epidemiology and Intervention Research Unit, Lilongwe, Malawi

Acknowledgements We thank Professor Naveed Sattar (University of Glasgow, UK) and Dr Tim McDonald (University of Exeter and Royal Devon and Exeter Hospital, UK) for helpful discussion. We thank all study participants.

Contributors MJN, AC, RN, GA, LB, BS and ATH researched the underlying data. $\mathrm{RG}$ and $\mathrm{AJ}$ drafted the initial manuscript with assistance from MJN. RG and $\mathrm{LR}$ analysed the data with assistance from BS and AJ. All authors revised the manuscript and provided helpful discussion.

Funding This work is funded by the National Institute of Health and Social Care (UK), NIHR Global Health Group 17/63/131. AJ is funded by an NIHR Clinician Scientist Award. ATH and BS are supported by the NIHR Exeter Clinical Research Facility.

Disclaimer The funders had no role in study design, data collection and analysis, decision to publish, or preparation of the manuscript.

Competing interests None declared.

Patient consent for publication Not required. 
Ethics approval The Ugandan cohort was approved by the Uganda Virus Research Institute Science and Ethics Committee and the Uganda National Council for Science and Technology. The Malawian study was approved by the National Health Sciences Research Committee of Malawi and the London School of Hygiene and Tropical Medicine Ethics Committee, UK. The Exeter 10,000 study was approved by the UK NHS Health Research Authority South West Ethics Committee. The Exeter Family Study was approved by the University of Exeter Research Ethics Committee, UK.

Provenance and peer review Not commissioned; externally peer reviewed.

Data availability statement Data from the EXTEND study are available through application to the Peninsula Research Bank (https://exetercrfnihr.org/about/exeter10000-prb/). For enquiries about access to the Exeter Family Study please contact BS (B.Shields@exeter.ac.uk).The MEIRU data are available through the LSHTM Research Data Compass (https://datacompass.Ishtm.ac.uk/961/).

Supplemental material This content has been supplied by the author(s). It has not been vetted by BMJ Publishing Group Limited (BMJ) and may not have been peer-reviewed. Any opinions or recommendations discussed are solely those of the author(s) and are not endorsed by BMJ. BMJ disclaims all liability and responsibility arising from any reliance placed on the content. Where the content includes any translated material, BMJ does not warrant the accuracy and reliability of the translations (including but not limited to local regulations, clinical guidelines, terminology, drug names and drug dosages), and is not responsible for any error and/or omissions arising from translation and adaptation or otherwise.

Open access This is an open access article distributed in accordance with the Creative Commons Attribution Non Commercial (CC BY-NC 4.0) license, which permits others to distribute, remix, adapt, build upon this work non-commercially, and license their derivative works on different terms, provided the original work is properly cited, appropriate credit is given, any changes made indicated, and the use is non-commercial. See: http://creativecommons.org/licenses/by-nc/4.0/.

\section{ORCID iDs}

Robert Newton http://orcid.org/0000-0001-6715-9153

Angus Jones http://orcid.org/0000-0002-0883-7599

\section{REFERENCES}

1 Kronmal RA, Cain KC, Ye Z, et al. Total serum cholesterol levels and mortality risk as a function of age. A report based on the Framingham data. Arch Intern Med 1993;153:1065-73.

2 Cooney MT, Dudina A, De Bacquer D, et al. HDL cholesterol protects against cardiovascular disease in both genders, at all ages and at all levels of risk. Atherosclerosis 2009;206:611-6.

3 Rader DJ, Hovingh GK. Hdl and cardiovascular disease. The Lancet 2014;384:618-25.

4 HPS2-THRIVE Collaborative Group, Landray MJ, Haynes R, et al. Effects of extended-release niacin with laropiprant in high-risk patients. N Engl J Med 2014;371:203-12.

5 AIM-HIGH Investigators, Boden WE, Probstfield JL, et al. Niacin in patients with low HDL cholesterol levels receiving intensive statin therapy. N Engl J Med 2011;365:2255-67.

6 Voight BF, Peloso GM, Orho-Melander M, et al. Plasma HDL cholesterol and risk of myocardial infarction: a Mendelian randomisation study. Lancet 2012;380:572-80.

7 NICE. Lipid modification - CVD prevention, 2019. Available: https:// cks.nice.org.uk/lipid-modification-cvd-prevention\#!topicSummary [Accessed 12 Jun 2020].

8 Miller WM, Nori-Janosz KE, Lillystone M, et al. Obesity and lipids. Curr Cardiol Rep 2005;7:465-70.

9 Delisle H, Ntandou G, Sodjinou R, et al. At-risk serum cholesterol profile at both ends of the nutrition spectrum in West African adults? The Benin study. Nutrients 2013;5:1366-83.

10 Asiki G, Murphy GAV, Baisley K, et al. Prevalence of dyslipidaemia and associated risk factors in a rural population in south-western Uganda: a community based survey. PLoS One 2015;10:e0126166.

11 Noubiap JJ, Bigna JJ, Nansseu JR, et al. Prevalence of dyslipidaemia among adults in Africa: a systematic review and metaanalysis. The Lancet Global Health 2018;6:e998-1007.

12 Oladapo OO, Salako L, Sodiq O, et al. A prevalence of cardiometabolic risk factors among a rural Yoruba south-western Nigerian population: a population-based survey. Cardiovasc J Afr 2010;21:26-31.

13 Njoroge A, Guthrie BL, Bosire R, et al. Low HDL-cholesterol among HIV-1 infected and HIV-1 uninfected individuals in Nairobi, Kenya. Lipids Health Dis 2017;16:110.
14 Kodaman N, Aldrich MC, Sobota R, et al. Cardiovascular disease risk factors in Ghana during the rural-to-urban transition: a crosssectional study. PLoS One 2016;11:e0162753

15 Soares ALG, Banda L, Amberbir A, et al. A comparison of the associations between adiposity and lipids in Malawi and the United Kingdom. BMC Med 2020;18:181.

16 Njelekela MA, Negishi H, Nara Y, et al. Obesity and lipid profiles in middle aged men and women in Tanzania. East Afr Med $J$ 2002;79:58-64.

17 Mykkänen L, Laakso M, Pyörälä K. Association of obesity and distribution of obesity with glucose tolerance and cardiovascular risk factors in the elderly. Int $J$ Obes Relat Metab Disord 1992;16:695-704.

18 Nguyen NT, Magno CP, Lane KT, et al. Association of hypertension, diabetes, dyslipidemia, and metabolic syndrome with obesity: findings from the National health and nutrition examination survey, 1999 to 2004. J Am Coll Surg 2008;207:928-34.

19 Reeder BA, Senthilselvan A, Després JP, et al. The association of cardiovascular disease risk factors with abdominal obesity in Canada. Canadian heart health surveys Research Group. CMAJ 1997;157(Suppl 1):S39-45.

20 Joshi SR, Anjana RM, Deepa M, et al. Prevalence of dyslipidemia in urban and rural India: the ICMR-INDIAB study. PLoS One 2014;9:96808.

21 Thomas GN, Ho S-Y, Lam KSL, et al. Impact of obesity and body fat distribution on cardiovascular risk factors in Hong Kong Chinese. Obes Res 2004;12:1805-13.

22 Mbalilaki JA, Hellènius M-L, Masesa Z, et al. Physical activity and blood lipids in rural and urban Tanzanians. Nutr Metab Cardiovasc Dis 2007;17:344-8.

23 Njelekela M, Kuga S, Nara Y, et al. Prevalence of obesity and dyslipidemia in middle-aged men and women in Tanzania, Africa: relationship with resting energy expenditure and dietary factors. Nutr Sci Vitaminol 2002;48:352-8.

24 Asiki G, Murphy G, Nakiyingi-Miiro J, et al. The general population cohort in rural south-western Uganda: a platform for communicable and non-communicable disease studies. Int $J$ Epidemiol 2013;42:129-41.

25 Crampin AC, Kayuni N, Amberbir A, et al. Hypertension and diabetes in Africa: design and implementation of a large population-based study of burden and risk factors in rural and urban Malawi. Emerg Themes Epidemiol 2016;13:3

26 Knight B, Shields BM, Hattersley AT. The Exeter family study of childhood health (EFSOCH): study protocol and methodology. Paediatr Perinat Epidemiol 2006;20:172-9.

27 Soares ALG, Banda L, Amberbir A, et al. Sex and area differences in the association between adiposity and lipid profile in Malawi. BMJ Glob Health 2019;4:e001542.

28 Murphy GA, Asiki G, Ekoru K, et al. Sociodemographic distribution of non-communicable disease risk factors in rural Uganda: a crosssectional study. Int J Epidemiol 2013;42:1740-53.

29 WHO. WHO steps surveillance manual, 2017.

30 Johnson JL, Slentz CA, Duscha BD, et al. Gender and racial differences in lipoprotein subclass distributions: the STRRIDE study. Atherosclerosis 2004;176:371-7.

31 van der Linden E, Meeks K, Beune E, et al. Dyslipidaemia among Ghanaian migrants in three European countries and their compatriots in rural and urban Ghana: the RODAM study. Atherosclerosis 2019;284:83-91.

32 Glew RH, Conn CA, Vanderjagt TA, et al. Risk factors for cardiovascular disease and diet of urban and rural dwellers in northern Nigeria. J Health Popul Nutr 2004:22:357-69.

33 Shisana O, Labadarios D, Rehle T. The South African National health and nutrition examination survey, 2012: SANHANES-1: the health and nutritional status of the nation. HSRC Press, 2014. Available: www.blueweaver.co.za [Accessed 29 Mar 2021].

34 Reiger S, Jardim TV, Abrahams-Gessel S, et al. Awareness, treatment, and control of dyslipidemia in rural South Africa: the HAALSI (health and aging in Africa: a longitudinal study of an indepth community in South Africa) study. PLoS One 2017;12:e0187347.

35 Sumner AE, Zhou J, Doumatey A, et al. Low HDL-cholesterol with normal triglyceride levels is the most common lipid pattern in West Africans and African Americans with metabolic syndrome: implications for cardiovascular disease prevention. CVD Prev Control 2010;5:75-80.

36 Watkins LO, Neaton JD, Kuller LH. Racial differences in high-density lipoprotein cholesterol and coronary heart disease incidence in the usual-care group of the multiple risk factor intervention trial. $A m \mathrm{~J}$ Cardiol 1986;57:538-45.

37 Hutchinson RG, Watson RL, Davis CE, et al. Racial differences in risk factors for atherosclerosis. Angiology 1997;48:279-90. 
38 Okosun IS, Liao Y, Rotimi CN, et al. Abdominal adiposity and clustering of multiple metabolic syndrome in white, black and Hispanic Americans. Ann Epidemiol 2000;10:263-70.

39 Brown CD, Higgins M, Donato KA, et al. Body mass index and the prevalence of hypertension and dyslipidemia. Obes Res 2000;8:605-19.

40 Taylor HA, Coady SA, Levy D, et al. Relationships of BMI to cardiovascular risk factors differ by ethnicity. Obesity 2010;18:1638-45.

41 Agyemang C, Addo J, Bhopal R, et al. Cardiovascular disease, diabetes and established risk factors among populations of subSaharan African descent in Europe: a literature review. Global Health 2009;5:7.

42 Agongo G, Amenga-Etego L, Nonterah EA, et al. Candidate Gene Analysis Reveals Strong Association of CETP Variants With High Density Lipoprotein Cholesterol and PCSK9 Variants With Low Density Lipoprotein Cholesterol in Ghanaian Adults: An AWI-Gen Sub-Study. Front Genet 2020;11:456661.

43 Brinton EA, Eisenberg S, Breslow JL. A low-fat diet decreases high density lipoprotein (HDL) cholesterol levels by decreasing HDL apolipoprotein transport rates. J Clin Invest 1990;85:144-51.
44 Hayek T, Ito Y, Azrolan N, et al. Dietary fat increases high density lipoprotein (HDL) levels both by increasing the transport rates and decreasing the fractional catabolic rates of HDL cholesterol ester and apolipoprotein (apo) A-I. Presentation of a new animal mode and mechanistic studies in human apo A-I transgenic and control mice. J Clin Invest 1993;91:1665-71.

45 Johnsson $\mathrm{H}$, Panarelli M, Cameron A, et al. Analysis and modelling of cholesterol and high-density lipoprotein cholesterol changes across the range of $\mathrm{C}$-reactive protein levels in clinical practice as an aid to better understanding of inflammation-lipid interactions. Ann Rheum Dis 2014;73:1495-9.

46 Woudberg NJ, Goedecke JH, Lecour S. Protection from cardiovascular disease due to increased high-density lipoprotein cholesterol in African black populations: myth or reality? Ethn Dis 2016;26:553-60.

47 Woudberg NJ, Lecour S, Goedecke JH. Hdl subclass distribution shifts with increasing central adiposity. J Obes 2019;2019:1-6.

48 Boateng D, Agyemang C, Beune E, et al. Cardiovascular disease risk prediction in sub-Saharan African populations - Comparative analysis of risk algorithms in the RODAM study. Int $\mathrm{J}$ Cardiol 2018;254:310-5. 


\section{Correction: Associations between low HDL, sex and cardiovascular risk markers are substantially different in sub-Saharan Africa and the UK: analysis of four population studies}

Greiner R, Nyrienda M, Rodgers L, et al. Associations between low HDL, sex and cardiovascular risk markers are substantially different in sub-Saharan Africa and the UK: analysis of four population studies. BMJ Glob Health 2021;6:e005222.

The published version misspelled co-authors name as Moffat Nyrienda and Beverly Shields. The correct name should be Moffat Nyirenda and Beverley Shields.

Open access This is an open access article distributed in accordance with the Creative Commons Attribution Non Commercial (CC BY-NC 4.0) license, which permits others to distribute, remix, adapt, build upon this work non-commercially, and license their derivative works on different terms, provided the original work is properly cited, appropriate credit is given, any changes made indicated, and the use is non-commercial. See: http://creativecommons.org/licenses/by-nc/4.0/.

(C) Author(s) (or their employer(s)) 2021. Re-use permitted under CC BY-NC. No commercial re-use. See rights and permissions. Published by BMJ.

BMJ Global Health 2021;6:e005222corr1. doi:10.1136/bmjgh-2021-005222corr1

(A) Check for updates 